\title{
MYSTERY OF MIMOSA PUDICA
}

\section{S. P. DHIR ${ }^{1}$, DEEPAK SALUNKE ${ }^{2}$, ARSHPREET KAUR ${ }^{3} \&$ SANJIV DHIR ${ }^{4}$}

${ }^{1}$ Former Medical Superintendent \& Professor of Ophthalmology, Govt Medical College, Chandigarh, India

${ }^{2,3}$ Department of Chemistry, Punjab University, Chandigarh, India

${ }^{4}$ Thapar University, Patiala, India

\begin{abstract}
Besides touch, warming etc., we found acetone and other lipid solvents ( Butyl alcohol, Octyl alcohol, petroleum etc.,) could also cause rapid drooping and folding of the leaves of Mimosa pudica. In contrast to generation of action potential for signal transduction, it is proposed that in Mimosa pudica (touch me not) Touch, heat and acetone lead to sudden drop of electrical resistance and loss of electric charge. In a while the resistance is restored like a Varistor with return of turgor in motor cells and opening of leaflets.
\end{abstract}

KEYWORDS: Mimosa Pudica, Lipid Solvents, Acetone, Leaf Movement Mechanism \& Varistor

Received: Oct 26, 2017; Accepted: Nov 16, 2017; Published: Dec 02, 2017; Paper Id.: IJBRDEC20178

\section{INTRODUCTION}

Mimosa pudica (Touch me not) is a creeping annual or perennial herb of the pea family Fabaceae, often grown for its curiosity value. The compound leaves fold inward and droop when touched or shaken and re-open a few minutes later [1]. The leaves close rapidly in response to stimuli, such as touching, warming, blowing, or shaking. These types of movements have been termed seismonastic movements. The stimulus is transmitted via action potentials to the pulvini of the plant, where contractile proteins and aquaporins induce the movement of water and electrolytes out of the cell. [2]

Volkov et al [3,4] after extensive study came to the conclusion that the movements in Mimosa pudica, such as the response to touch, appear to be regulated by electrical, hydro dynamical and chemical signal transduction.

Based on our findings we propose a different mechanism for rapid drooping, folding of leaflets and recovery. The motor cells maintain turgor pressure, because of electric charge which keeps ion channels closed. Loss of electric charge leads to opening of ion channels and loss of turgor. When charge is regenerated ion channels close and recovery takes place. A similar process has been reported in bottle gourd tendril $[5,6]$.

\section{MATERIALS AND METHODS}

One to two month old well watered plants of Mimosa pudica were used for the study. For the purpose of this study five parts of the plant namely; stem, pulvinus, leaf stalk and petiole and leaflets were studied.

Experiment \# 1: Touch sensitive points were mapped on the plant. Tooth pick and forceps were used to produce touch sensation.

Experiment \# 2: Acetone drop was gently applied on various parts of the plant to map acetone sensitive 
points.

\section{OBSERVATIONS}

Experiment \# 1.It was found that both pulvinus and petiole were sensitive to touch resulting in drooping of the leaf and folding of the leaflets respectively. No effect was seen on touching the stem, leafstalk or leaflets. Affected parts namely pulvinus and petiole recovered in 10-15 minutes.

Experiment \# 2. Application of acetone had no effect on the stem. It caused drooping of the stalk on application to pulvinus. Application of acetone drop to leafstalk also led to drooping of the leaf at pulvinus. Application of acetone to the junction of leafstalk with leaflets led drooping of pulvinus, as well as folding of leaflets. Application of acetone to petiole led to folding of the leaflets. If the stimulus was applied to the middle of the leaflet the leaflets folded both in upward and downward direction. Application of acetone to leaflets had no effect on the leaflets. Affected parts namely pulvinus and petiole recovered in 10-15 minutes.

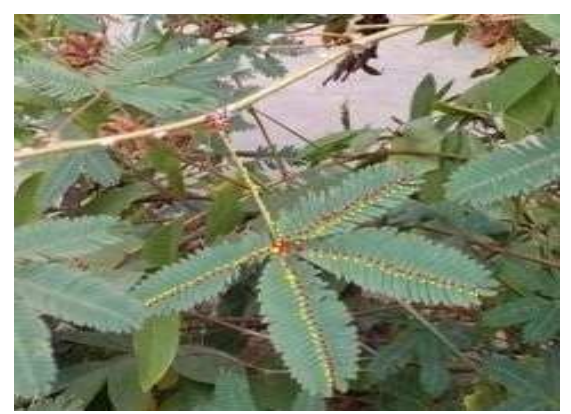

Figure \# 1 Touching the petiole and pulvinus at various points (Red dots) led to fast folding of leaflets and drooping of the leaf. Application of acetone to petiole, pulvinus and leaf stalk at various points (Yellow dots) had similar effect.

\section{DISSCUSSIONS}

The findings of acetone and other lipid solvents as stimulus are unexpected. Besides finding another experimental convenient tool of chemical stimulus it indicated involvement of lipids. Application of acetone to leafstalk causing drooping of the pulvinus indicated a fast mode of communication between the pulvinus, petiole and leafstalk. It is proposed that the turgor of the mimosa pudica leaf is maintained by generation of electric charge and closure of charge gated ion channels. Disruption of lipids by acetone causes drop of electrical resistance, loss of electric charge and opening of ion channels. Loss of turgor of motor cells results in drooping of the leaf and folding of leaflets. A similar process has been described in rapid coiling of tendril of bottle gourd plant [5,6]. The loss of electric charge in senso-motor cells in bottle gourd plant tendril leads to opening of charge gated channels and loss of turgor of the cells. Possibly similar phenomenon takes place in senso-motor cells in the pulvinus of the mimosa pudica. Generation of electric charge, leads to closure of charge gated ion channels and restoration of normal turgid condition of the plant.

It is hypothesized that acetone and other lipid solvents disrupt the phospholipids in the plasma membrane leading to loss of insulation between two charged surfaces.

\section{CONCLUSIONS}

Plasma membrane maintains a positive charge on its outer surface in the form of a plate and lipids provide 
insulation from the interior of the cell. In contrast to generation of action potential for transduction of signal in majority of situations, it is loss of charge which is utilized for transduction of signal. Besides an electric charge based communication network in the stem of the plant is also strongly suspected.

Phospholipids reorganize to provide insulation and regeneration of electric charge results in closure of ion channels with restoration of turgidity in the leaves. The whole process works like a self resetting varistor.

\section{ACKNOWLEDGEMENTS}

Acknowledgements re due to Dr. G.K.Khuller for technical advice and Mr. Ravi Kumar for experimental assistance.

\section{REFERENCES}

1. Raven, Peter H.; Evert, Ray F.; Eichhorn, Susan E. (January 2005). "Section 6 Physiology of Seed Plants: 29. Plant Nutrition and Soils". Biology of Plants (7th ed.). New York: W. H. Freeman and Company. p. 639

2. Vanden Driessche, Thérèse (2000). "Nutations in Shoots and in Desmodium Lateral Leaflets, Nyctinastism and Seismonastism in Mimosa pudica. Comparison and Evolution of Morphology and Mechanism". Biological Rhythm Research. 31 (4): 451468..

3. Alexander G Volkov, Justin C Foster, Kara D Baker, Vladislav S Markin. Mechanical and electrical anisotropy in Mimosa pudica pulviniPlant Signal Behav. 2010 Oct; 5(10): 1211-1221.

4. Alexander G Volkov,Justin C Foster, Vladislav S Markin. Signal transduction in Mimosa pudica: biologically closed electrical circuits. Plant Cell Environ. 2010 May;33(5):816-27

5. Dhir S P. Electric Charge Signaling in Plant Tendrils. International Journal of Scientific and Research Publications, Volume 6, Issue 8, August 2016.

6. Dhir S P. Bottle Gourd Plant Tendril-Role of Electric Charge in Rapid Contact Coiling. International Journal of Scientific and Research Publications, Volume 7, Issue 11, November 2017 
